\title{
Effect of Opening Size on Wind-Driven Cross Ventilation
}

\author{
Lip Kean Moey ${ }^{1 *}$, Yao Horng Sing ${ }^{2}$, Vin Cent Tai ${ }^{1}$, Tze Fong Go ${ }^{3}$, Yaw Yoong \\ Sia $^{1}$
}

${ }^{1}$ Centre for Modelling and Simulation, Faculty of Engineering, Built Environment \& Information Technology,

SEGi University, Selangor, MALAYSIA

${ }^{2}$ Faculty of Engineering, Built Environment \& Information Technology, SEGi University, Selangor, MALAYSIA

${ }^{3}$ Centre for Advance Materials and Intelligent Manufacturing, Faculty of Engineering, Built Environment \& Information Technology, SEGi University, Selangor, MALAYSIA

*Corresponding Author

DOI: https://doi.org/10.30880/ijie.2020.13.06.009

Received 17 July 2020; Accepted 13 January 2021; Available online 31 August 2021

\begin{abstract}
The opening size is important to the ventilation of building because various opening sizes affects the ventilation performance for building. Therefore, the objective of this study is to investigate the effect of opening size on indoor airflow characteristics of naturally ventilated building model. The numerical simulation with steady RANS equations was used. A total of six different opening ratios, namely 4:1, 2:1, 1:1, 1:2, 4:9 and 1:4 were considered in this study. The results of mesh independence study and model validation were also in good agreement with previous study. The simulation results show that velocity and pressure of the indoor air, ventilation rate, and pressure coefficient are highly dependent on the opening ratio. The velocity and pressure contour indicate that the lower the opening ratio, the higher the velocity and subsequently lower pressure inside the building. In addition, the pressure coefficient and ventilation rate are also increased as the opening ratio decreases. Besides, the results indicate that percentage increase in ventilation rate of opening ratio $4: 1$ and $2: 1,2: 1$ and $1: 1$, and $1: 1$ and $1: 2$ is higher than those of opening ratio for $1: 2$ and $4: 9,4: 9$ and 1:4. The study concluded that pairing a large outlet and small inlet leads to increase in better ventilation rate for building.
\end{abstract}

Keywords: Natural ventilation, opening ratio, ventilation rate, pressure coefficient

\section{Introduction}

In some Southeast Asian countries, the main energy source for power generation is fossil fuels. According to previous research, the use of fossil fuels has accounted for 75\% of total energy demand [1]. Due to over-reliance on fossil fuels, this will lead to severe pollution and possible climate change, as well as temperature increase. Thus, mechanical ventilation and air conditioning are used to obtain thermal comfort, which results in the use of vast quantities of fossil fuel and causes harm to environment [2]. Therefore, it is inevitable to choose other ways to avoid over-reliance on fossil fuel. An alternative method namely natural ventilation can be used to minimize the use of mechanical ventilation and air conditioning in buildings. Not only that, it can also minimize the use of fossil fuels, protect the environment from destruction and human health.

Natural ventilation is one of the most significant and effective strategies for the passive cooling of the building [3]. This is because natural ventilation uses natural forces to replace indoor air with fresh outdoor air [4]. The natural forces that used to ventilate the building are wind and buoyancy-driven. Through replacement of air, indoor air that contains odor, bacteria, dust, accumulated moisture and other contaminants can be removed [5]. Hence, natural ventilation can be applied to regulate indoor air and protect the occupant's health [6]. 
Natural ventilation can be divided into three different types which are single-sided ventilation, cross ventilation and stack ventilation. For single-sided ventilation, it contains one or more openings on same façade of the building. In other words, it can be understood that air will enter and exit the building through the same opening [7]. Cross ventilation will have two openings but will be on opposite sides of each other and driven by wind to generate the airflow [8]. The windows prevailing in the wind are called windward facade, which is where the air enters, and the other side is called leeward facade, which is where the air leaves. One thing to note is that inlet must be located in a high-pressure area (positive pressure) and outlet must be located in a low-pressure area (negative pressure) to achieve better ventilation. For stack ventilation, buoyancy-driven is used to generate the airflow. The stack ventilation also has two openings that one is located at lower position and another at the higher position. The opening in the lower position allows air to enter, and then the air is discharged from the opening in the upper position. Hence, the stack ventilation happens when there are variations in density between indoor and outdoor air, caused by the difference in temperature between indoor and outdoor or difference in height [9].

A study was conducted to examine the influence of various opening shapes on cross ventilation in an isolated building [10]. The indicators used to determine ventilation performance were flow rate and passive pollutant concentration. A total of three different opening shapes, called squared, horizontally long and vertically long openings was considered and their inlet and outlet opening dimensions are the same. Throughout the study, the results show that the performance of cross ventilation in reducing pollutants increases as the ratio of the height to width of the opening increases. In addition, in all the three cases, the horizontally long opening is the most polluted, but vertically long opening shape has the highest ventilation performance and is also the most effective in all the three cases.

The size of the opening plays a significant role in building ventilation. Previous study investigate the pressure coefficient at the openings, the number of airflow rate changes, and the qualitative distribution of internal flow at the different opening area [3]. In this study, two different opening sizes were used for analysis, namely the window area is equivalent to $10 \%$ and $25 \%$ of the floor area. It was found that changes in window size and wind direction angle would affect natural ventilation conditions, thereby affecting significant changes in ventilation rate and pressure coefficient, $C p$. The results also show that as the window size increases, the pressure coefficient difference, $\Delta C p$ was also increases.

The 3D steady Reynolds-averaged Navier-Stokes (RANS) equations associated with SST k- $\omega$ turbulence models were used to evaluate the influence parameters of the volume flux in isolated buildings [11]. The validation was also conducted based on the numerical and experimental results achieved by the previous studies. The studied parameters of this study were the aspect ratios of the opening and their positions for different wind directions. This study considered a total of seven window aspect ratios with identical opening area, six different wind directions, and eight different vertical and horizontal positions on the leeward wall. The results show that small changes in window position and size can influence natural ventilation through increasing volume flux. In addition, the results also show that when the wind direction is greater than or equal to $45^{\circ}$, the volume flow rate is independent of the opening aspect ratios.

The Reynolds Stress Model (RSM) turbulence model was used to investigate three different items to understand the airflow characteristics, namely the effect of aperture size on the leeward wake and windward vortex, discovered the information about the above-ground flow that can be retrieved from pressure measurement on ground, and finally explored accuracy of CFD simulation [12]. The aperture size in this study was also be changed from a narrow crack to the large aperture. It was found through research that when changing the size of the aperture, the pressure distribution and flow pattern will change. Furthermore, if the opening size exceeds certain value, the wake on leeward and vortex on windward side disappeared.

A study was conducted to investigate the effect of porosity on airflow characteristics and discharge coefficient by using CFD analysis and wind tunnel experiments [13]. The porosity range that used to study was $0.4 \%$ to $0.6 \%$. For CFD analysis, it shows that as the porosity increases, the blockage of the stream tube will no longer arise in the upstream area of the opening, which will lead to an increase in discharge coefficient and eliminate the contraction of flow. Furthermore, CFD analysis also shows a good agreement with results of wind tunnel that the higher the porosity, the greater the discharge coefficient.

The aforementioned studies presented above have shown that the opening is a significant parameter that will affect the ventilation rate, flow pattern, and other parameters of the building. Therefore, the appropriate opening size for cross ventilation needs to be investigated to further improve cross ventilation performance. In addition, the opening size of the literature review can be further modified to better understand the influence of the opening size on cross ventilation. Moreover, parameters such as $\triangle C p$ and ventilation rate can be analyzed to further understand the indoor airflow characteristics at different opening sizes. In summary, the parameters such as ventilation rate, $\triangle C p$ and others change significantly when the opening size changes. However, study related to the effect of opening size on cross ventilation is limited in literature. Therefore, this paper uses numerical simulation to investigate the effect of opening size on cross ventilation for an isolated building.

In Section 2, detailed information on numerical studies will be discussed, such as model validation, boundary conditions, mesh independence study, computational domains, solver settings, and models. Furthermore, simulation results of different opening ratios will be discussed in section 3. At last, the conclusion of the overall study will be presented in section 4 . 


\section{Numerical Study}

\subsection{Model}

In this study, an isolated building model was used to investigate indoor air flow characteristics. The dimension of the model was $100 \mathrm{~mm} \times 100 \mathrm{~mm} \times 80 \mathrm{~mm}$ (length $\times$ width $\times$ height), which is the reduced scale of 1: 200, and it corresponds to the full scale of $20 \mathrm{~m}$ x $20 \mathrm{~m}$ x $16 \mathrm{~m}$. In addition, the thickness of the building model was set at $2 \mathrm{~mm}$, with two windows facing each other at the center of windward and leeward façade. Figure 1 shows the dimension and symmetry plan of reference case [14]. Furthermore, the case study is further modify based on the reference case. Figure 2 was the building model used in this study, where the size of inlet opening remains the same, while the size of outlet opening changes from large opening ratio to small opening ratio. Table 1 shows the dimension and opening ratio in each case.

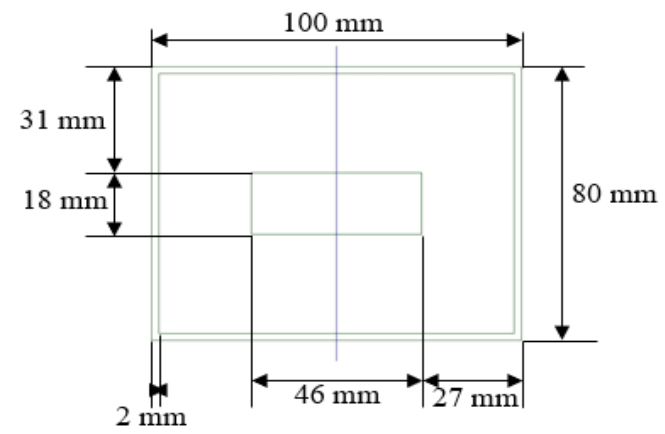

(a)

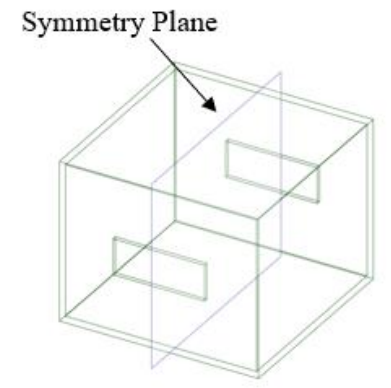

(b)

Fig. 1 - (a) Model dimensions (b) Symmetry plan of reference building model

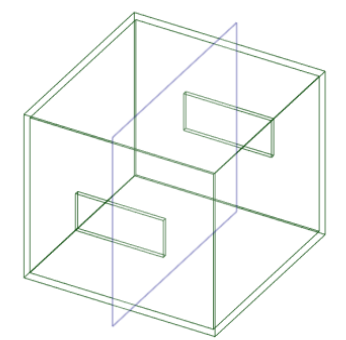

Case 1(Reference Case)

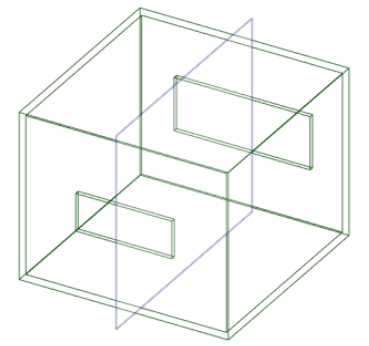

Case 4

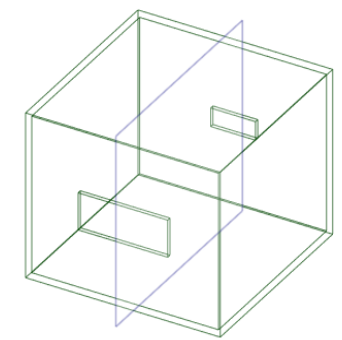

Case 2

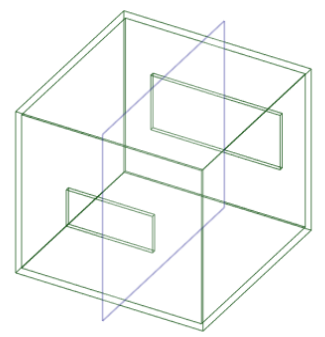

Case 5

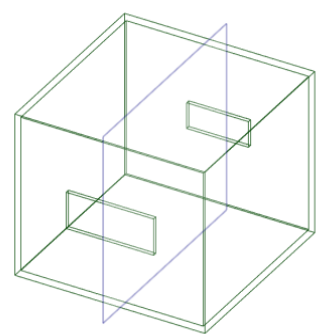

Case 3

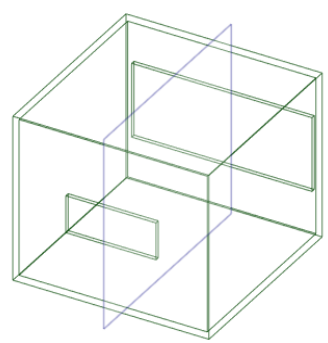

Case 6

Fig. 2 - Isometric view for all six different cases

Table 1 - Dimension of openings and opening ratio for all six different cases

\begin{tabular}{cccc}
\hline & $\begin{array}{c}\text { Inlet Opening Size, mm } \\
\text { (Width x Height) }\end{array}$ & $\begin{array}{c}\text { Outlet Opening Size, mm } \\
\text { (Width x Height) }\end{array}$ & $\begin{array}{c}\text { Opening Ratio } \\
\text { (Inlet to Outlet ratio) }\end{array}$ \\
\hline Case 1 & $46 \times 18$ & $46 \times 18$ & $1: 1$ \\
Case 2 & $46 \times 18$ & $23 \times 9$ & $4: 1$ \\
Case 3 & $46 \times 18$ & $32.52 \times 12.73$ & $2: 1$ \\
Case 4 & $46 \times 18$ & $65.04 \times 25.45$ & $1: 2$ \\
Case 5 & $46 \times 18$ & $69 \times 27$ & $4: 9$ \\
Case 6 & $46 \times 18$ & $92 \times 36$ & $1: 4$ \\
\hline
\end{tabular}

*Reference case 


\subsection{Computational Domain}

In order to simulate actual wind field around the building model, a computational domain with dimensions of $0.9 \mathrm{~m}$ x $1.544 \mathrm{~m}$ x $0.48 \mathrm{~m}$ was created. The computational domain was based on the reference from Ramponi [14]. According to previous studied, the length of the windward facade was set at $3 \mathrm{H}$, the length of the leeward facade was set at $15 \mathrm{H}$, and the length of the top and sides were set at $5 \mathrm{H}$, where $\mathrm{H}$ represents the height of reference building model, which is $80 \mathrm{~mm}$ [14], [15], [16]. The upstream was fixed at $3 \mathrm{H}$ to limit the occurrence of unexpected slope in approach flow profile [14], [17], [18]. Figure 3 shows the computational domain and its dimension in isometric view.

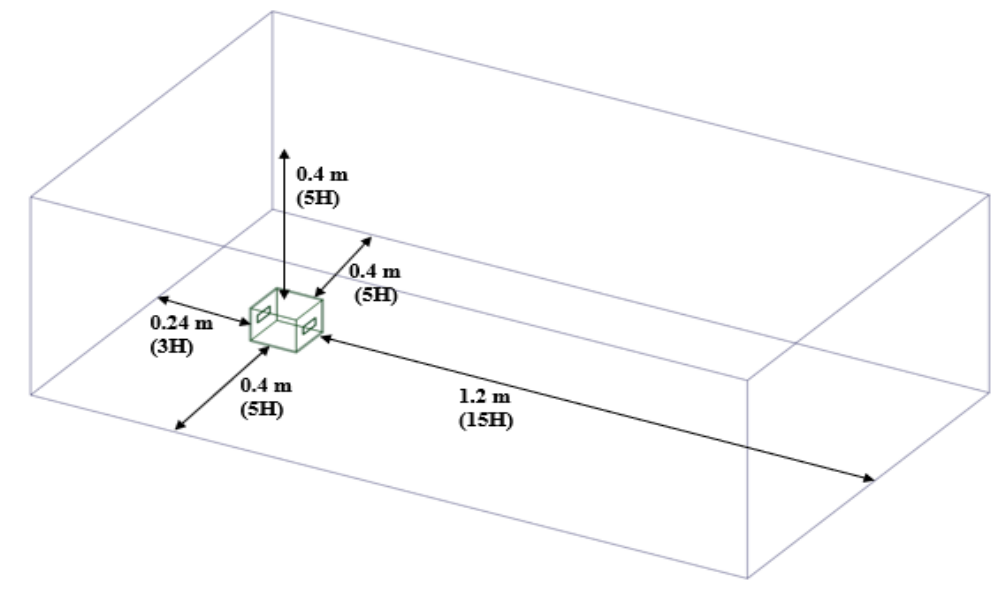

Fig. 3 - Dimension of computational domain

\subsection{Atmospheric Boundary Layer Condition (ABL)}

According to Richards and Hoxey [19], the measured vertical profile of mean wind speed, turbulent dissipation rate and turbulent kinetic energy are used to define boundary conditions on inlet plane in the simulation. In addition, a logarithmic law was used to define the inlet wind velocity profile. The equation for the law of logarithm is shown in Equation (1). The atmospheric boundary layer (ABL) friction velocity, $u_{\text {ABL }}^{*}$ was calculated through Equation (2), where the reference wind speed, $U_{\text {ref }}=6.97 \mathrm{~m} / \mathrm{s}$, von Karman constant, $\boldsymbol{\kappa}=0.4$, aerodynamic roughness height, $z_{0}=0.00003 \mathrm{~m}$ and the vertical height coordinate from the ground, $z=0.08 \mathrm{~m}$.

$$
\begin{gathered}
U(z)=U_{A B L}^{*} \ln \left(\frac{z+z_{o}}{z}\right) \\
U_{A B L}^{*}=\frac{U_{r e f} \times k}{\ln \left(\frac{z+z_{o}}{z}\right)}
\end{gathered}
$$

The turbulent kinetic energy $k(z)$ in Equation (3) was calculated by using mean wind speed, $U(z)$ in Equation (1), and measured streamwise turbulent intensity, $I_{u}(z)$. Previous studies have been conducted to identify the best value of $\alpha$ [14], [16]. As recommended by Tominaga et al, $\alpha=1$ was used in this study. For the turbulent dissipation rate, it was calculated by using Equation (4). Through controlling the turbulent kinetic energy and turbulent dissipation rate, specific dissipation rate was calculated through Equation (5). The $C_{\mu}$ shown in Equation (5) is an empirical constant which equals to 0.09 . For ground and building surfaces, standard wall functions developed by Launder and Spalding and sand-grain based roughness modification by Cebeci and Bradshaw's are used [20], [21]. The values of roughness parameters, such as sand-grain roughness height, $k_{s}$ and roughness constant, $C_{s}$ were determined according to their relationship with the $z_{0}$ which has been obtained through study of Blocken et al [17]. The ground sand-grain roughness height, $k_{s}=0.0006 \mathrm{~m}$ was obtained through Equation (6) where the roughness constant, $C_{s}$ was set at 0.5. The standard wall functions also applied for building surface with $k_{s}=0$.

$$
\begin{gathered}
k(z)=\alpha\left(I_{u}(z) U(z)\right)^{2} \\
\varepsilon(z)=\frac{\left(U_{A B L}^{*}\right)^{3}}{k\left(z+z_{o}\right)} \\
\omega(z)=\frac{\varepsilon(z)}{C_{\mu} k(z)}
\end{gathered}
$$




$$
k_{s=} \frac{9.793 z_{o}}{C_{s}}
$$

The zero static pressure was implemented to outlet plane. For top and side façade boundary condition, zero gradient and zero normal velocity condition of all variables were applied. In other words, zero sheared condition was implemented. At last, symmetry type was fixed for the symmetry plane.

\subsection{Solver Setting}

The CFD simulation was conducted using ANSYS 2019 R3. In this study, 3D steady-state RANS equation was solved in conjunction with k- $\omega$ SST turbulence model. The k- $\omega$ SST turbulence model was chosen because it was able to obtain results similar to the PIV experiments conducted by Karava [14], [22]. The material used in this study was air with density of $1.225 \mathrm{~kg} / \mathrm{m}^{3}$ and viscosity of $1.789 \times 10^{-5} \mathrm{~kg} / \mathrm{ms}$. The boundary conditions for inlet, outlet, top, side, ground, symmetry, and model in this study were inserted according to the user-defined (UDF) ABL conditions. Furthermore, the SIMPLE algorithm was used for all simulations in this study. For the spatial discretization, Green-Gauss Node Based was chosen. The second order was assigned to pressure, momentum, turbulent kinetic energy, and turbulent dissipation rate [14], [23]. The warped-face gradient correction and high order term relaxation were selected to improve accuracy of the results. The standard initialization was chosen for this study. The convergence was expected to be achieved when all scaled residuals stable and reached a minimum value of $10^{-4}$ for $k$, and $10^{-5}$ for $x, y, z$, and $\omega$.

\subsection{Mesh Independence Study}

In this study, mesh independence study was conducted to eliminate the discretization error. Three different numbers of cells representing coarse, medium, and fine meshing were selected. The cell count was 327609 cell counts (coarse meshing), 657737 cell counts (medium meshing), and 813868 cell counts (fine meshing). The mesh independence study was based on streamwise wind speed ratio (U/Uref) along the centerline of inlet and outlet opening. The reference wind speed (Uref) of $6.97 \mathrm{~m} / \mathrm{s}$ was used. PIV wind tunnel experiment results by Karava was chosen to compare with simulation results [22]. Figure 4 shows the three different cell counts and PIV wind tunnel experiment results by Karava. Through the comparison, it shows that the fine mesh with 813868 cell counts is most similar to the PIV wind tunnel experiment results. Therefore, the fine mesh was retained for further analysis.

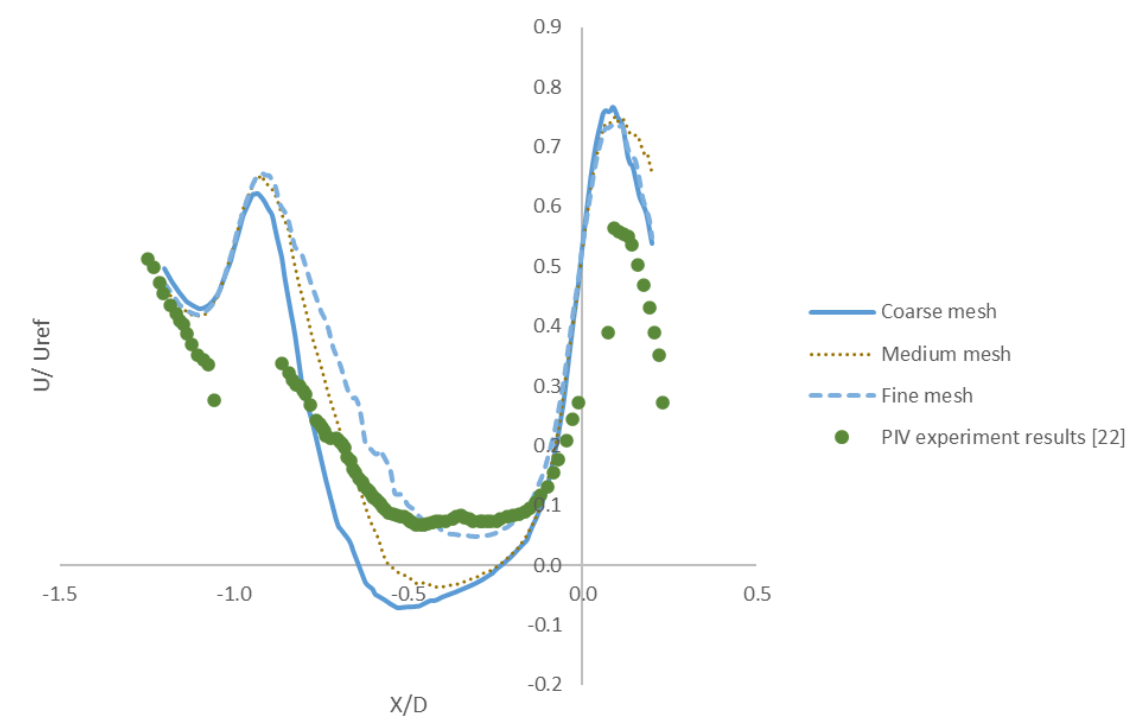

Fig. 4 - Simulation results from three different cell counts and PIV experiment result by Karava [22]

\subsection{Model Validation}

The results obtained for reference case then compared with simulation by Ramponi [14]. This comparison was performed in order to validate the accuracy of simulation results. As shown in Figure 5, the validation was performed using the contours by Ramponi. Through this model validation, it shows that the contour obtained from the simulation looks similar to that obtained by Ramponi. Therefore, it can be concluded that the reference case simulation result is acceptable. 


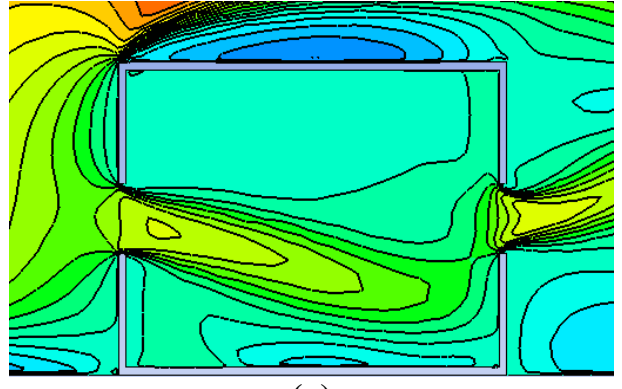

(a)

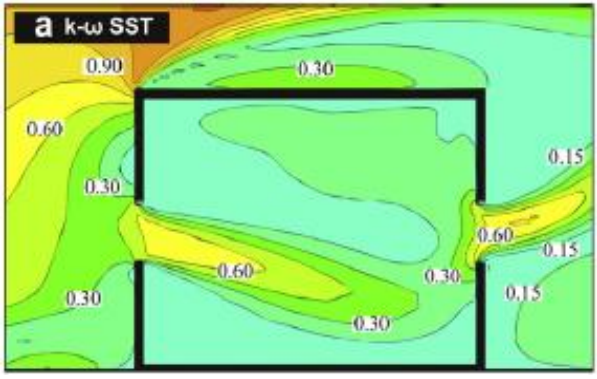

(b)

Fig. 5 - Validation based on velocity contour (a) Simulation result (b) Result by Ramponi [14].

\section{Results and Discussion}

\subsection{Velocity and Pressure}

From Figure 6, it clearly indicates that the internal air velocity increase when the opening ratio decreased. This result shows a good agreement with Bernoulli principle, where pressure decreases when velocity increases. The lower opening ratio allows incoming air to move at high speed and leave the building model without undergoing a sudden decrease in velocity. However, a larger opening ratio causes air to undergo a sudden decrease in velocity when passing through the building model. This sudden decrease of air velocity limits the volume of air passes through the opening and causes air to accumulate inside the building model, thereby directly increase pressure inside the building model and around the opening. Subsequently, increase of pressure forces the air to pass through the opening for better ventilation. This explains larger opening ratio has the highest velocity at the outlet and lowest at the inlet. Case 1 has higher velocity and pressure at the opening and inside the building model. On the other hand, Case 6 has lower velocity and pressure at the opening and inside the building model. In other words, in the case of different inlet and outlet opening size, when the inlet opening size is larger than the outlet, the higher velocity is on the side with smaller opening size, and vice versa.
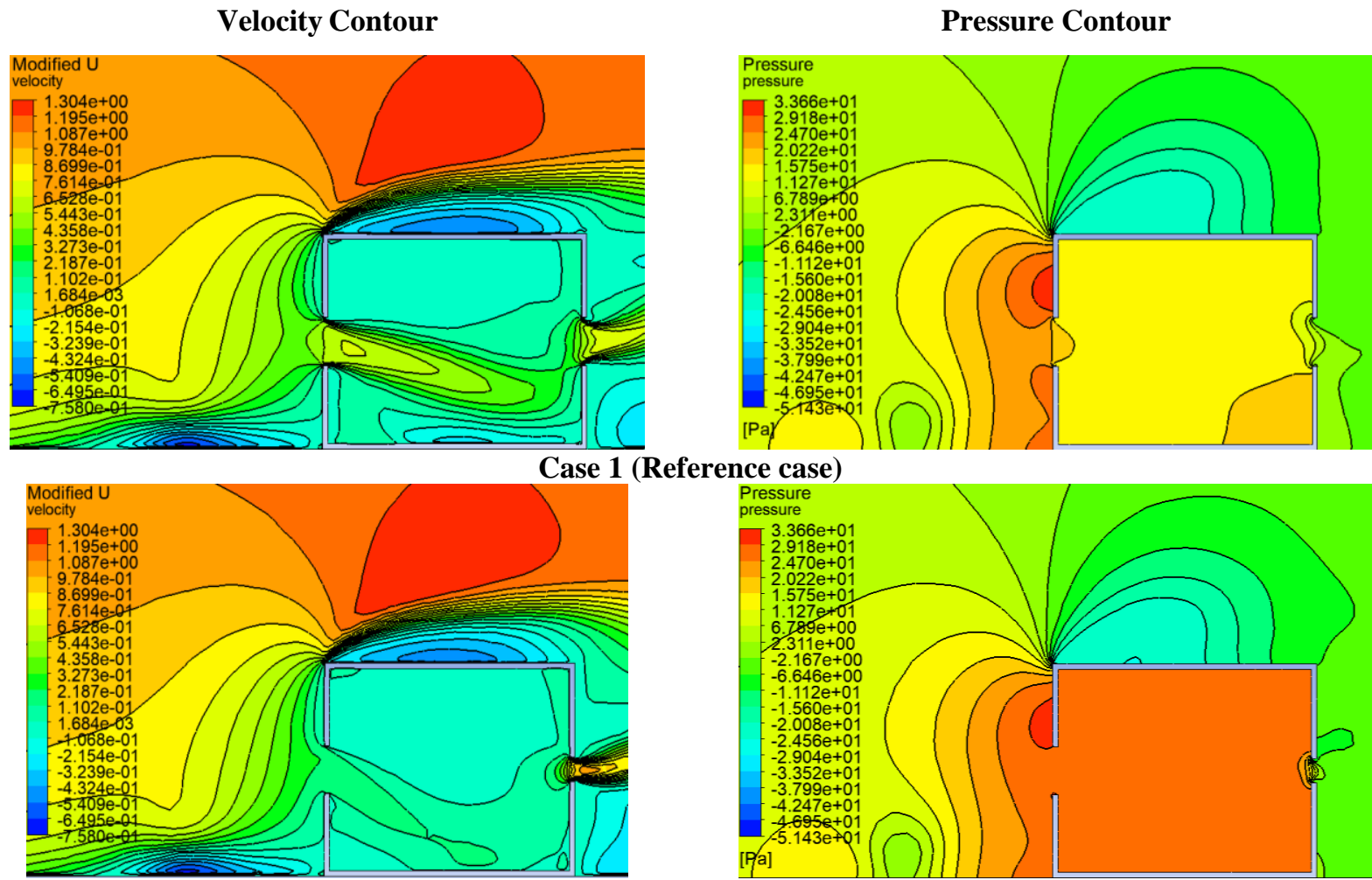

Case 2

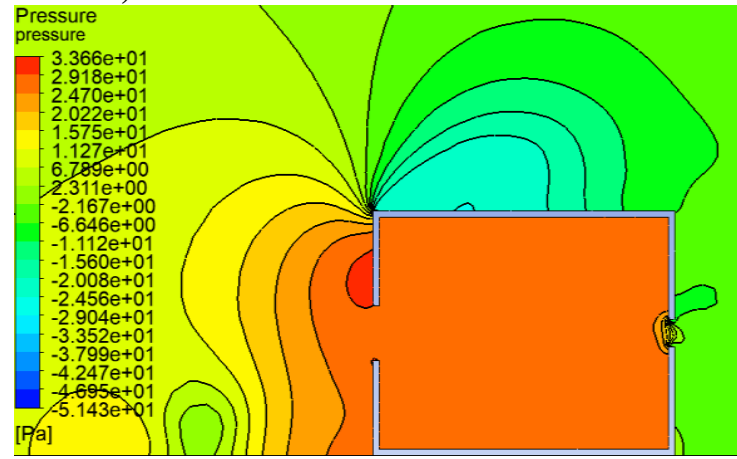



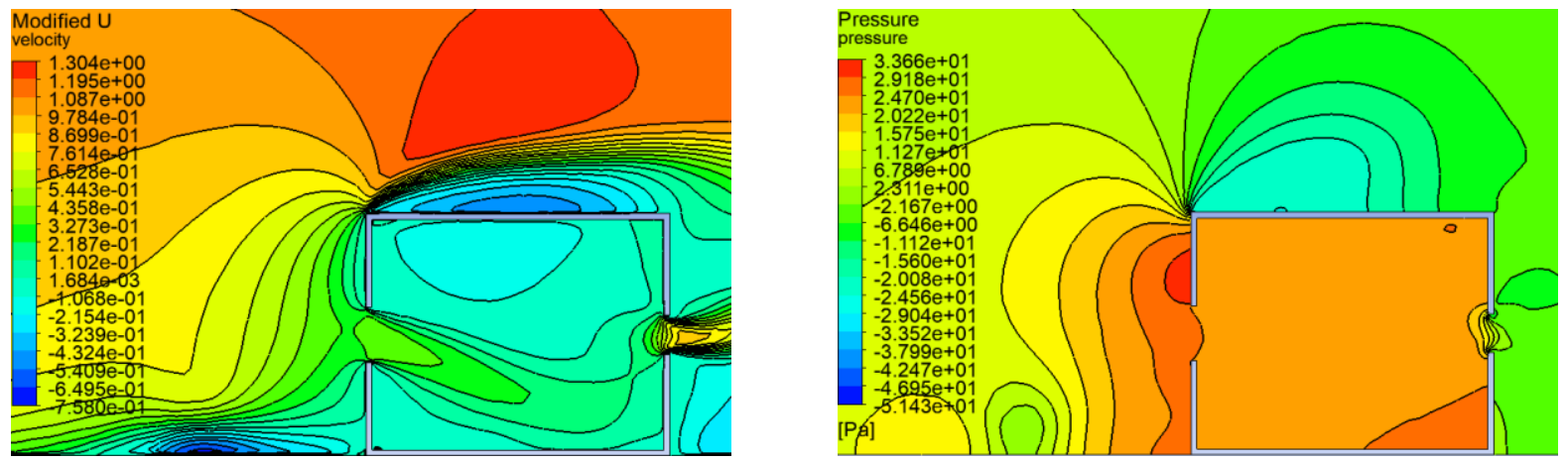

Case 3
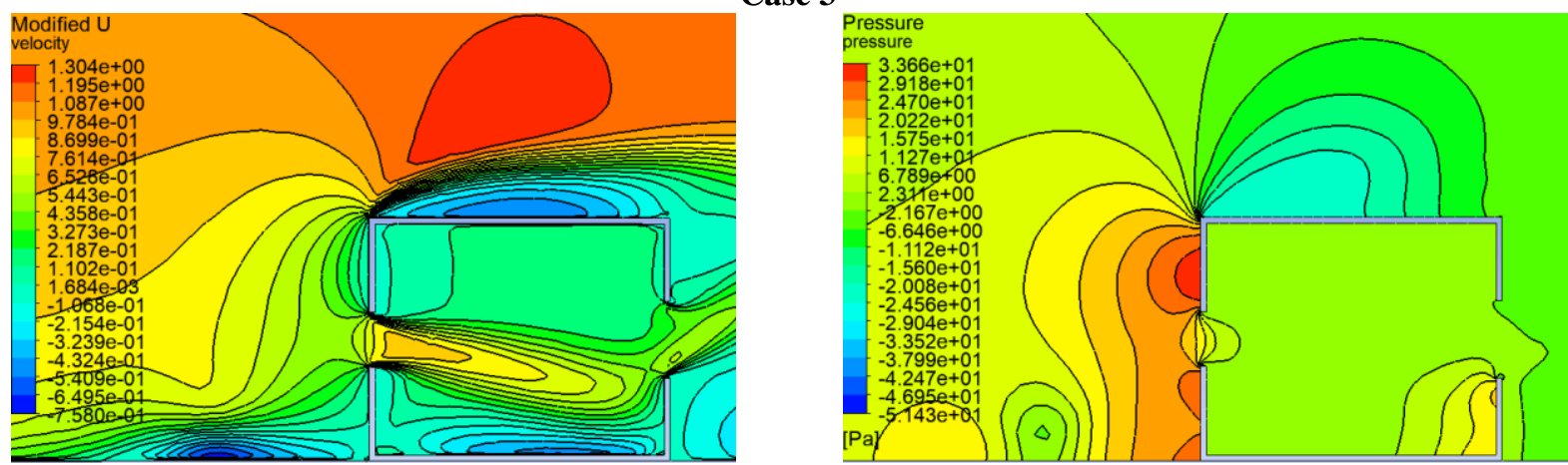

Case 4
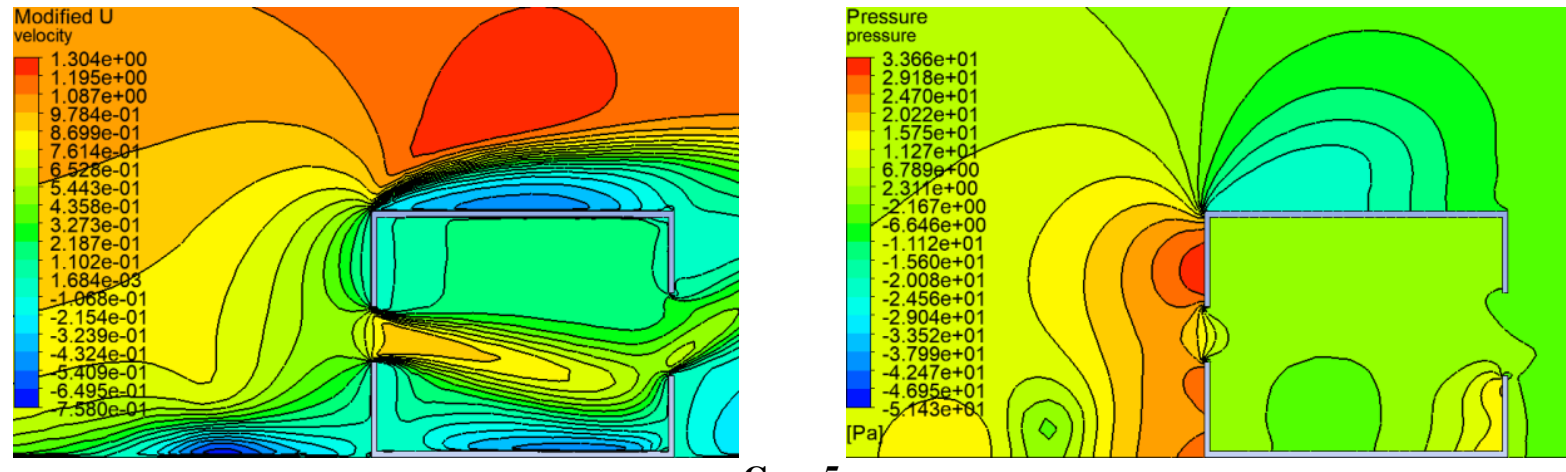

Case 5
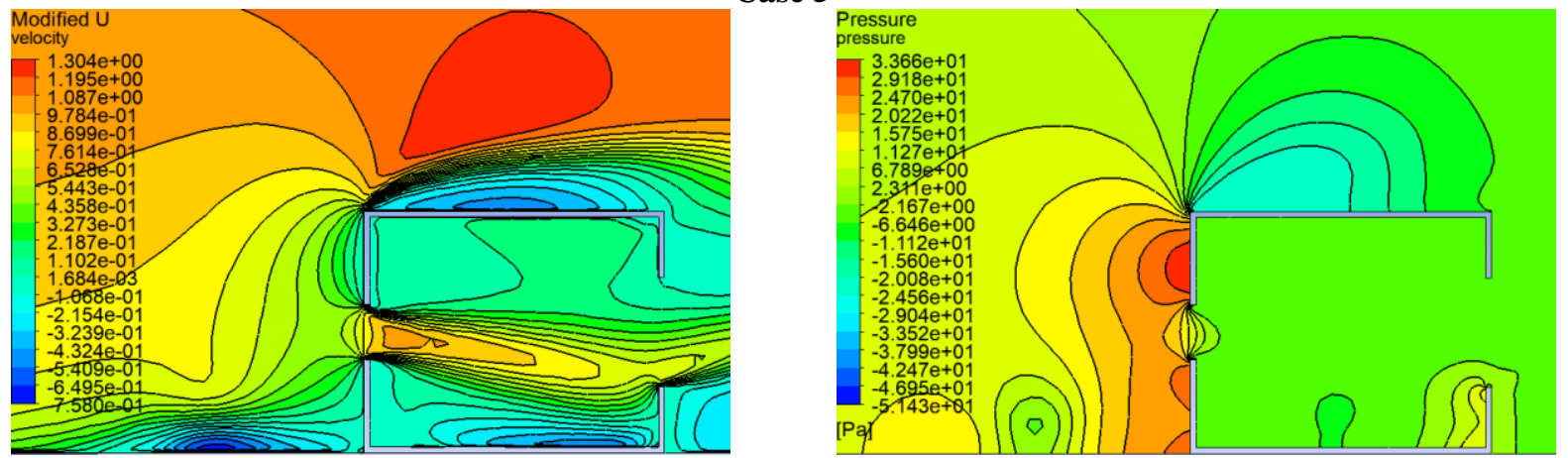

Case 6

Fig. 6 - Velocity and pressure contour at six different opening ratios

\subsection{Pressure Coefficient $(C p)$}

The $C p$ can be obtained through Equation (7) where density of air, $\rho=1.225 \mathrm{~kg} / \mathrm{m}^{3}$, and reference velocity, $V_{\text {ref }}=$ $6.97 \mathrm{~m} / \mathrm{s}$, local building pressure, $P$, and reference pressure, $P_{r}$ [24]. Then, the $\triangle C p$ inside the building model can be calculated.

$$
C_{p}=\frac{P-P_{r}}{\frac{1}{2} \rho V_{r e f}^{2}}
$$


According to Amanuel Tecle, the lower the opening ratio, the higher the pressure drop, $\triangle C p$ inside the building model [25]. Through calculation, the results indicate that value of $\triangle C p$ increases when opening ratio decreases. The contour in Figure 7 is in great agreement with results obtained by Amanuel Tecle [25].
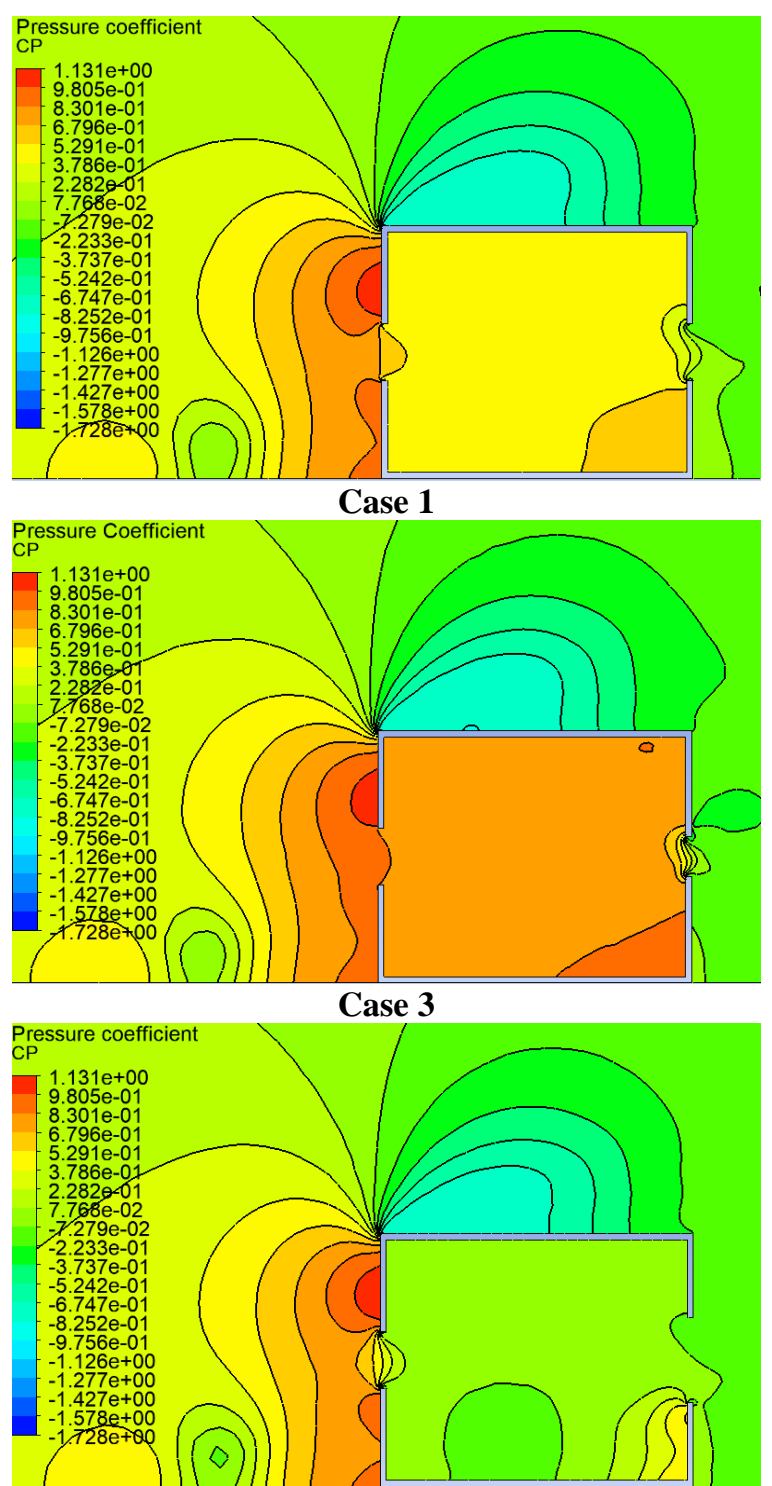

Case 5

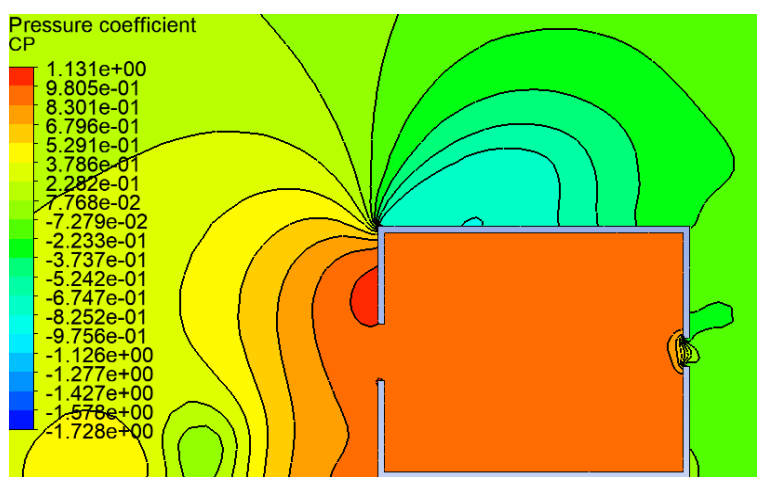

Case 2

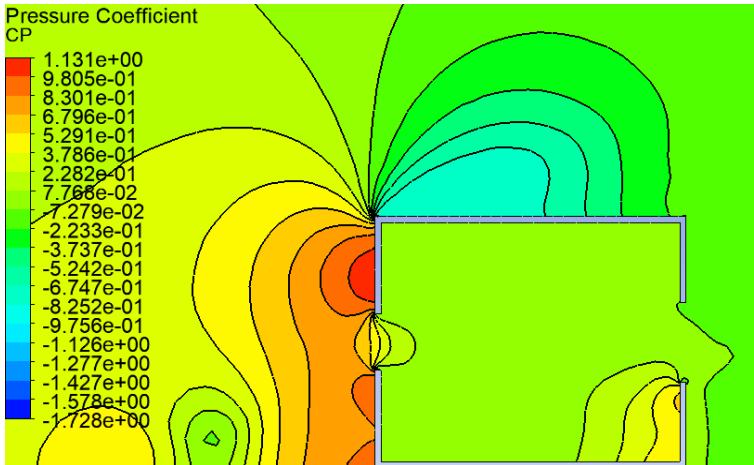

Case 4

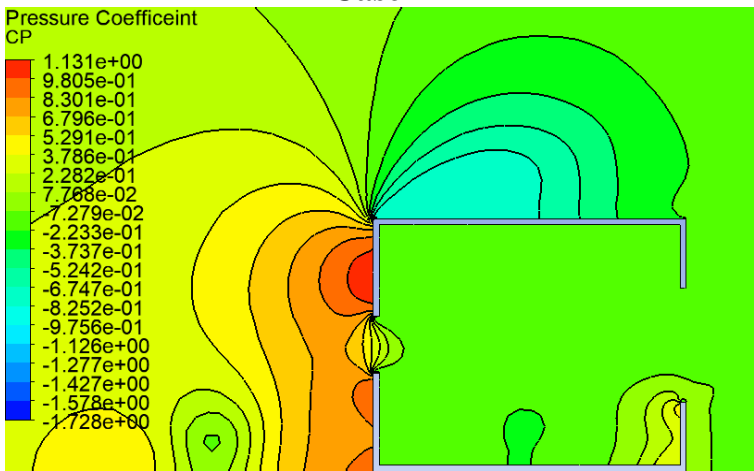

Case 6

Fig. 7 - Contour of $C p$ for six different opening ratios

\subsection{Ventilation Rate}

The ventilation rate for each case can be calculated through the following formula [24]:

$$
\begin{gathered}
C_{Q}=C_{d} \times V_{\text {ref }} \times\left(\Delta C_{p}\right)^{\frac{1}{2}} \\
C_{a}=\frac{C_{Q}}{1+C_{Q}} \\
Q=C_{a} \times V_{\text {ref }} \times A_{e}
\end{gathered}
$$

Flow coefficient, $C_{Q}$, can be calculated by using Equation (8) with discharge coefficient, $C_{d}=0.62$ and difference of pressure coefficient, $\triangle C p$ that has been discussed in the previous section. The actual flow coefficient, $C_{a}$ was calculated by using Equation (9). At last, the ventilation rate can be obtained through Equation (10) with effective opening area, $A_{e}$. 
Figure 8 shows that Case 6 and Case 2 has the highest and lowest ventilation rate, respectively. Through comparison, it clearly shows that when the opening ratio is greater or equal to 1 , the percentage increase in ventilation rate is ranged from $100 \%$ to $250 \%$. However, when the opening ratio is less than 1 , the percentage increase in ventilation rate is below $10 \%$. In other words, as the opening ratio continues to decrease, the percentage increase in the ventilation rate is not significant. Furthermore, the ventilation rate is directly proportional to $\triangle C p$ since the higher the $\Delta C p$, the higher the ventilation rate. Hence, the reduction of opening ratio leads to an increase in $\triangle C p$ and ventilation rate which subsequently promote better indoor ventilation performance.

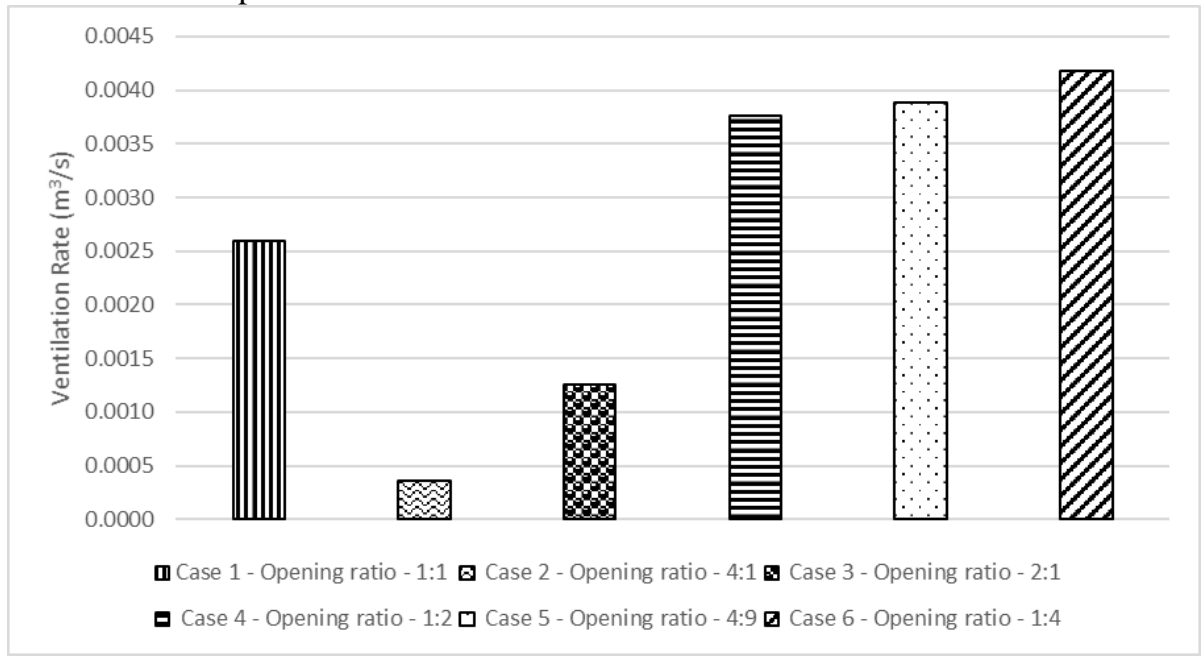

Fig. 8 - Ventilation rate under different window opening size

\section{Conclusion}

In the current study, airflow characteristics under different opening ratios were investigated and analyzed. The 3Dsteady RANS equation in this study was solved associated with SST k- $\omega$ turbulence model. The mesh independence study and model validation were also carried out and were in good agreement with the results obtained by previous study. Based on the velocity and pressure inside of the building model, the results show a good agreement with Bernoulli Principle that lower pressure results in higher velocity. Furthermore, when opening size of the inlet is greater than the outlet, the higher velocity is on the side with the smaller opening size, and vice versa. Besides, when opening ratio decreases, $\triangle C p$ increases which leads to higher ventilation rate. When opening ratio is greater than 1 , the percentage increase in ventilation rate is ranged from $100 \%$ to $250 \%$. Nevertheless, when the opening ratio is less than 1 , the percentage increase in ventilation rate is less than $10 \%$. In other words, as the opening ratio decreases, the percentage increase in the ventilation rate is not significant. In addition, the study also shows that pairing a larger outlet opening with smaller inlet opening increases the velocity at the inlet, thereby reducing the pressure inside the building model and obtaining a better ventilation rate. Therefore, it can be concluded that internal airflow is highly dependent on opening ratio. For future research, it is recommended to include various opening shapes, wind incidence angles, and wind speeds to further examine the effect of openings on natural cross ventilation and subsequently improve ventilation performance.

\section{Acknowledgement}

The project is funded by the Ministry of Higher Education Malaysia, under the Fundamental Research Grant Scheme (FRGS). Grant No: FRGS/1/2017/TK07/SEGI/02/1.

\section{References}

[1] Moey, L. K., Goh, K. S., Tong,D. L., Chong, P. L., Adam, M. \& Ahmad, K. A. (2020). A review on current energy usage and potential of sustainable energy in southeast asia countries. Journal of Sustainability Science and Management, 15(2), 89-107

[2] Gan, G.H. (2000). Effective depth of fresh air distribution in rooms with single-sided natural ventilation. Energy and Buildings, 31(1), 65-73

[3] Sacht, H. \& Lukiantchuki, M. A. (2017). Windows size and the performance of natural ventilation. Procedia Engineering, 196, 972-979

[4] Khan, N. , Su, Y. \& Riffat, S. B. (2008). A review on wind driven ventilation techniques. Energy and Buildings, 40(8), 1586-1604

[5] Bangalee, M. Z. I. , Lin, S. Y. \& Miau, J. J. (2012). Wind driven natural ventilation through multiple windows of a building: A computational approach. Energy and Buildings, 45, 317-325

[6] Yang, C., Shi, H., Yang, X. \& Zhao, B. (2010). Research on flow resistance characteristics with different 
window/door opening angles. HVAC \& R Research, 16(6), 813-824

[7] Mohamed, M. F., King, S., Behnia, M. \& Prasad, D. (2011). A study of single-sided ventilation and provision of balconies in the context of high-rise residential buildings. World Renewable Energy Congress 2011, Linkoping, Sweden, 1954-1961

[8] Hawendi, S. \& Gao, S. (2016). Investigation of opening positions on the natural ventilation in a low-rise building by CFD analysis. $3^{\text {rd }}$ International Conference On Fluid Flow, Heat and Mass Transfer, Ottawa, Canada, paper no. 151

[9] Abd. Wahab, I., Kadir, A., Ismail, L. K. (2016). Opening design and position effect on building natural stack effect and cross ventilation. International Journal of Engineering and Techincal Research, 5(1), 13-22

[10] Tehrani, F. B., Verki, S. M., \& Gholamalipour, M. (2020). Impact of opening shape on airflow and pollutant dispersion in a wind-driven cross-ventilated model building: Large eddy simulation. Sutsainable Cities and Society, 61, 1-20

[11] Derakhshan, S., \& Shaker, A. (2017). Numerical study of the cross-ventilation of an isolated building with different opening aspect ratios and locations for various wind directions. International Journal of Ventilation, 16(1), 42-60

[12] Kobayashi, T., Sandberg, M., Kotani, H. \& Claesson, L. (2010). Experimental investigation and CFD analysis of cross-ventilated flow through single room detached house model. Building and Environment, 45(12), 2723-2734.

[13] Kurabuchi, T., Akamine, Y., Ohba, M., Endo, T., Goto, T. \& Kamata, M. (2006). A study on the effects of porosity on discharge coefficient in cross-ventilated buildings based on wind tunnels experiments. International Journal of Ventilation, 5(1), 67-78

[14] Ramponi, R. \& Blocken, B. (2012). CFD simulation of cross-ventilation for a generic isolated building: impact of computational parameters. Building and Environment, 53, 34-48

[15] Franke, J., Hellsten, A., Schlünzen, H. \& Carissimo, B. (2007). Best practice guideline for the CFD simulation of flows in the urban environment. ISBN 3-00-018312-4

[16] Tominaga, Y., Mochida, A., Yoshie, R., Kataoka, H., Nozu, T., Yoshikawa, M. \& Shirasawa, T. (2008). AIJ guidelines for practical applications of CFD to pedestrian wind environment around buildings. Journal of Wind Engineering and Industrial Aerodynamics, 96(10-11), 1749-1761

[17] Blocken, B., Stathopoulos, T. \& Carmeliet, J. (2007). CFD simulation of the atmospheric boundary layer: Wall function problems. Atmospheric Environment, 41(2), 38-252

[18] Blocken, B., Carmeliet, J. \& Stathopoulos, T. (2007). CFD evaluation of wind speed conditions in passages between parallel buildings-effect of wall-function roughness modifications for the atmospheric boundary layer flow. Journal of Wind Engineering and Industrial Aerodynamics, 95(9-11), 941-962

[19] Richards, P. J. \& Hoxey, R. P. (1993). Appropriate boundary conditions for computational wind engineering models using the K- $€$ turbulence model. Journal of Wind Engineering and Industrial Aerodynamics, 46\&47, 145153

[20] Launder, B. E. \& Spalding, D. B. (1974). The numerical computation of turbulent flows. The Numerical Computation of Turbulent Flows, 3(2), 96-116

[21] Cebeci, T. \& Bradshaw, P. (1977). Momentum Transfer In Boundary Layers. New York: Hemisphere Publishing Corporation

[22] Karava, P., Stathopoulos, T. \& Athienitis, A. K. (2011). Airflow assessment in cross-ventilated buildings with operable façade elements. Building and Environment, 46(1), 266-279

[23] Van Hooff, T., Blocken, B. \& Tominaga, Y. (2017). On the accuracy of CFD simulations of cross-ventilation flows for a generic isolated building: Comparison of RANS, LES and experiments. Building and Environmet, 114, 148-165

[24] Swami, M. \& Chandra, S. (1987). Procedures for calculating natural ventilation airflow rates in buildings. ASHRAE Final Report, FSEC-CR-163-86

[25] Tecle, A., Bitsuamlak, G. T. \& Jiru, T. E. (2012). Wind-driven natural ventilation in a low-rise building: A boundary layer wind tunnel study. Building and Environment, 59, 275-289 